\title{
Evolution of cesium and strontium contamination deposited on vines
}

\author{
C. Madoz-Escande, C. Colle and C. Adam \\ IPSNDPRE/SERLAB, CE Cadarache, 13108 Saint-Paul-lez-Durance, France
}

\begin{abstract}
Vine plant contamination by means of dry aerosols (Cs-137 and Sr-90) was carried out on two large scale lysimeters taken from an on-site vinc plantation (limestone silty loamy soil) in order to forecast, both short and long term consequences of an accident occurring at a pressurised water reactor on some common agricultural products. Initial contamination (of the soil and the plant) was performed at two vegetative stages: one at the "late flowering" stage for one lysimeter, the other at the "beginning of ripening" stage for the second lysimeter. A total but non-lethal defoliation test was carried out on one vine plant in order to estimate the efficiency of this countermeasure method in reducing contamination at harvest. The influence of rain during the vegetative stages was analysed. For the first 6 years following deposition, root absorption of two radionuclides was examined: the consequences of initial contamination on different parts of the plant (bunches, leaves and shoots) were assessed as a function of time after cach harvest. Monitoring of migration in soil and bioavailability was also undertaken. Correlation tests between the activities found in the plants and the behaviour of radionuclides in soil (bio-availability of the stable and radioactive elements, migration of radio-nuclides) were performed.
\end{abstract}

\section{AIMS}

The aim of this study is to forecast the short (foliar contamination) and long (root uptake) term consequences of an accident occurring at a nuclear pressurised water reactor on vine plantation byproducts. To this end, a series of experiments was carried out in order to:

- reproduce agricultural surface contamination through radioactive aerosols (Cs-137 and Sr-90), similar to those that would be released during a severe accident;

- to quantify the amount of activity that would be found in the first harvest as a function of the vegetative stage of plants at the time of contamination; and,

- to follow behaviour through future harvests and in soil.

\section{EXPERIMENTAL CONTEXT}

\section{The soil:}

The agricultural surfaces studied are represented by large-scale monoliths of soi $(1.8 \mathrm{~m} \times 1.8 \mathrm{~m} \times 1.4 \mathrm{~m}$ deep), extracted from an on-site vine plantation in 1992. They were taken at Tricastin (in the Rhône valley). The soil is of an alluvial limestone type (limestone silty loamy soil). Its main physico-chemical characteristics are given in Table 1.

Table 1. Main soil properties.

CEC: Cationic exchange capacity

\begin{tabular}{cccccccc}
\hline $\begin{array}{c}\mathrm{pH}(\mathrm{KCl}) \\
{\left[\mathrm{pH}\left(\mathrm{H}_{\mathbf{2}} \mathbf{O}\right)\right]}\end{array}$ & $\begin{array}{c}\mathrm{CEC} \\
\text { meq/100g }\end{array}$ & $\begin{array}{c}\text { Organic } \\
\text { matter } \\
(\%)\end{array}$ & $\begin{array}{c}\text { Total } \\
\text { limestone } \\
(\%)\end{array}$ & $\begin{array}{c}\text { Sand } \\
(\%)\end{array}$ & $\begin{array}{c}\text { Load } \\
(\%)\end{array}$ & $\begin{array}{c}\text { Chy } \\
(\%)\end{array}$ & $\begin{array}{c}\text { Clay type } \\
(\text { composition } \\
\text { in \%) }\end{array}$ \\
\hline 7.3 & 10.6 & 3.2 & 24.9 & 13.5 & 36.8 & 21.6 & $\begin{array}{c}\text { Hlite/mica }(9.3) \\
\text { Kaolinite }(3.0) \\
\text { Chlorite }(5.0) \\
\text { Smectite/llite (4.3) }\end{array}$ \\
\hline
\end{tabular}




\section{Climate simulation:}

The soil blocks were placed in metal cases equipped with a dual bottom system, made up of a porous separation and a water tank placed in the lower end of the lysimeter. This porous bottom, made up of clay tiles enables water exchange between the lysimeter soil and the water tank. The pressurising or the depressurising of this water tank enables water table movements to be reproduced. Experiments on these lysimeters were carried out in a greenhouse where the climatic conditions at the site of origin were reproduced (relative humidity, rainfall, temperature, sunlight). The underground part had separate temperature control in order to reproduce natural conditions found in the soil [1].

\section{Plant matter:}

Each lysimeter possessed 2 young vine plants. These plants received specific treatments as follows.:

- Just before contamination, one of the 2 contaminated vine plants at the "beginning of ripening" stage had its bunches protected from direct deposit in order to assess bunch contamination with time resulting from translocation of radio-nuclides from the leaves to the bunches. The other vine plant had part of its leaves protected from direct deposit, in order to estimate in addition, the participation of translocation in these leaves, it was also used to determine the effect from rainwater washing occurring 6 days after contamination.

- One of the two vine plants contaminated in the "late flowering" stage underwent defoliation 7 days after contamination in order to assess the effect of this process on the radio-nuclide content in different parts of vine to the grape harvest. The other plant was used to study the effect from, rainwater washing occurring 8 days after contamination.

Throughout the experiment the soil was not cultivated which enabled vertical migration (due to rains) to be studied for $\mathrm{Cs}$ and $\mathrm{Sr}$ in the soil.

\section{Contamination:}

Aerosols representative of those released after a serious accident were generated using an induction furnace. These simulated aerosols that would be released in the case of a serious accident occurring from a pressurised water reactor (PWR) with core meltdown (at around $3,000^{\circ} \mathrm{C}$ ). Aerosols were generated in a water saturated atmosphere using a mixture of elements corresponding to the main materials found in a 900 MWe reactor: the nuclear fuel (in the form of uranium oxide), the reactor core structure materials, the components of the cladding containing the fuel and the control bars. Cesium-137 and strontium- 90 are included in this mixture. These aerosols have a mean aerodynamic diameter of around $3.5 \mu \mathrm{m}$. Their mean radionuclide content is $4 \%$ for caesium and $5 \%$ for strontium. They contain less than $1 \%$ of uranium and are highly soluble in rainwater with around $95 \%$ of cesium and $85 \%$ of strontium found in solution after a few hours.

The experimental protocol for the studies on lysimeters was as follows:

1. after production, aerosols were transferred to the lysimeters where they were deposited on the soils and plants (each lysimeter only received one contamination);

2. after contamination, rainfall events simulated natural conditions; and,

3. cesium and strontium was measured for 5 consecutive years in soils and plants.

\section{Sample treatment:}

Upon grape maturity, the different parts of the grapes were analysed separately. The grapes were pressed to give juice and then wine was produced. After drying in an oven at $60^{\circ} \mathrm{C}$ the samples were mineralised. Soil cores were taken, down to a depth of between 30 and $50 \mathrm{~cm}$, using a soil bore steps of around $1 \mathrm{~cm}$. The available fractions of caesium and strontium contained in the soils were determined using ammonium acetate (1N).

Cs- 137 was measured by $\gamma$ spectrometry using a germanium detector. The $\mathrm{Sr}-90$, was analysed by liquid scintillation after a radiochemical extraction [2]. 


\section{RESULTS AND DISCUSSION}

\subsection{Foliar contamination}

\subsubsection{Contamination at the "late fowering" vegetative stage}

At the moment of contamination (in 1995), the total deposit on lysimeters was $70 \mathrm{MBq} / \mathrm{m}^{2}$ for Cs-137 and $55 \mathrm{MBq} / \mathrm{m}^{2}$ for $\mathrm{Sr}-90$. The interception coefficient $\left(\mathrm{Bq} \cdot \mathrm{m}^{-2} / \mathrm{Bq} \cdot \mathrm{m}^{-2}\right.$ ) for each radioactive nuclide was calculated by comparing the total leaf activity per $\mathrm{m}^{2}$ of plantation and the total deposit (soil + plants) per $\mathrm{m}^{2}$. It was identical for both radioactive nuclides and is around $40 \pm 2 \%$.

The $\mathrm{Cs} / \mathrm{Sr}$ ratio for leaves after the first rain is greatly reduced which indicates greater removal of cesium than that of strontium. The retention coefficient, defined as the percentage of radionuclide remaining on the plants after the first rain, was $45 \%$ for Cs-137 and $58 \%$ for Sr-90. Subsequent rainfalls had little impact. After grape harvest, there is more $\mathrm{Cs}-137$ than $\mathrm{Sr}-90$ in the edible parts of the bunches. Zehnder [3], despite a different experimental protocol, noted, as in this study, that translocation from leaves to the bunches is much higher in the case of $\mathrm{Cs}-137$ than $\mathrm{Sr}-90$. For staiks, the $\mathrm{Cs} / \mathrm{Sr}$ ratio is near to 1 (Figure 1). The distribution of $\mathrm{Cs}-137$ and $\mathrm{St}-90$ in grape bunches shows that there is a higher $\mathrm{Sr} 90$ content in the stalk and that Cs-137 is mainly accumulated in the juice (Figure 2). The transformation of juice into wine leads to a contamination loss that should not be ignored: $35 \%$ of Cs-137 and $60 \%$ of Sr-90 is lost. In the juice, the global transfer coefficient (i.e. fraction of deposit in juice) is defined as being the ratio:

$$
\mathrm{CTg}=\frac{\text { juice activity }(\mathrm{MBq} / \mathrm{kg}) \times \text { juice yield }\left(\mathrm{kg} / \mathrm{m}^{2} \text { plantation }\right)}{\text { activity deposited onplants per } \mathrm{m}^{2} \text { plantation }\left(\mathrm{MBq} / \mathrm{m}^{2}\right)}
$$

It is around $3 \times 10^{-2}$ for $\mathrm{Cs}-137$ and $4.5 \times 10^{-3}$ for $\mathrm{Sr}-90$.

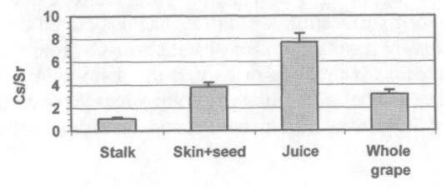

Figure $1 \mathrm{Cs} / \mathrm{Sr}$ ratio in different elements of the grape bunches at harvest.

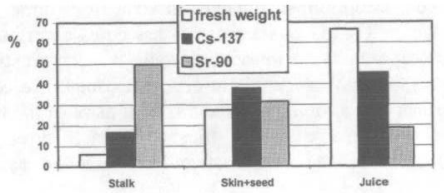

Figure 2 Fresh weight $\mathrm{Cs}-137$ and $\mathrm{Sr}-90$ distribution percentage in the different elements of grape bunches at harvest.

After the grape harvest, the leaves and shoots having been contaminated show an Sr-90 activity 1.6 times greater than Cs-137, which is due both to a more efficient reduction through washing in the case of caesium and to a higher translocation of caesium from the leaves to the other parts of the plant. In addition to this, leaf contamination is greater than that for the shoots, which is probably due to better interception of the initial deposit. However, the $\mathrm{Cs} / \mathrm{Sr}$ ratio in leaves and in shoots having grown after contamination shows that cesium translocation is around 10 times greater than for strontium.

Total defoliation of one of the 2 vine plants 7 days after contamination and after the first rain fall, did not result in any noticeable difference in caesium or strontium concentration in bunches in the year of contamination. In order to judge the efficiency of this type of process defoliation must be carried out much sooner following contamination: 2 days later, for example [4]. 


\subsubsection{Contamination at the "beginning of ripening" vegetative stage}

At the time of contamination (September 1994), the deposit was around $100 \mathrm{MBq} / \mathrm{m}^{2}$ for $\mathrm{Cs}-137$ and $75 \mathrm{MBq} / \mathrm{m}^{2}$ for $\mathrm{Sr}-90$. The first samples taken 2 days after the contamination show rapid translocation to bunches and leaves protected from direct deposit (Figure 3). Interception of these two radionuclides was greater for the leaf cover than for the bunches.

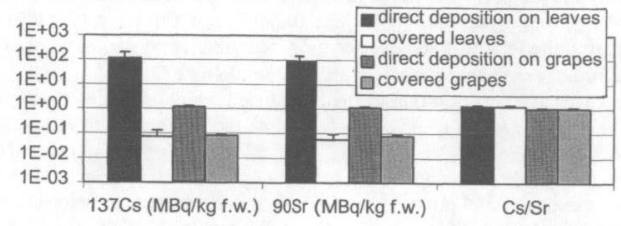

Figure $3 \mathrm{Cs}-137$ and Sr-90 concentration in bunches and in leaves 2 days after contamination

The changing $\mathrm{Cs} / \mathrm{Sr}$ ratio between contamination and harvest ( 30 days later) in leaves subjected to direct deposition shows that rain removed more Cs-137 than Sr-90. The influence of washing is greater at the beginning and levels out through time. Where bunches subject to direct deposition are concerned (contamination and rain), the increase of the $\mathrm{Cs} / \mathrm{Sr}$ ratio is low: the washing of $\mathrm{Cs}-137$ by rain is compensated for by translocation. On the other hand, for grapes protected from direct deposition, mass activity of contamination increases continually up until grape harvest: by a factor of 20 for Cs- 137 and by a factor of only 1.5 for $\mathrm{Sr}-90$, which is due to translocation of Cs-137 being higher than that of Sr-90. At harvest, strontium in bunches is $90 \%$ from direct deposit on the grapes and $10 \%$ from translocation. However, Cs-137 contamination has equal contribution for translocation. Carini [5], has also noted that seed contamination for a comparable vegetative stage mainly results from translocation of $\mathrm{Cs}$ from the leaves to bunches, despite a different contamination protocol. At the time of harvest the distribution of caesium and strontium in the different parts of the bunches subject to or protected from direct deposition is given in Table 2. The grapes subject to direct deposition were rinsed beforehand to estimate the proportion of the deposit that could be removed easily.

Table 2 The Cs-137 and Sr-90 distribution at the time of harvest in bunches with or without direct deposition at the "beginning of ripening" stage

\begin{tabular}{|c|c|c|c|c|c|}
\hline \multirow{4}{*}{$\begin{array}{l}\text { Bunches protected from the direct } \\
\text { deposition }\end{array}$} & & Stalk & Skin+ seed & Juice & Rinsing water \\
\hline & Fresh mass (\%) & 7 & 30 & 63 & \\
\hline & Cs-137 (\%) & 15 & 46 & 39 & \\
\hline & Sr-90 (\%) & 17 & 7 & 77 & \\
\hline \multirow{3}{*}{$\begin{array}{l}\text { Bunches subject to direct } \\
\text { deposition }\end{array}$} & Fresh mass (\%) & 7 & 23 & 70 & \\
\hline & Cs-137 (\%) & 17 & 43 & 28 & 12 \\
\hline & $\mathrm{Sr}-90(\%)$ & 10 & 60 & 20 & 10 \\
\hline
\end{tabular}

The transformation of juice into wine leads to a $30 \%$ loss for Cs-137 and $45 \%$ loss for Sr-90.

\subsection{Root uptake}

During the years following the soil deposit the ground was not cultivated, in order to monitor in parallel with the vine plant contamination, the migration of Cs-137 and Sr-90 in soil.

In the years following contamination, the parts most contaminated by $\mathrm{Cs}-137$ and $\mathrm{Sr}-90$ was the stalks, then "skin+seed" and finally the juice. However, a greater caesium contamination (Figure 4) was observed than for strontium (Figure 5) during the first years, with caesium concentrations declining 
through time and levelling out during the $5^{\text {th }}$ year of root transfer. In the case of strontium the concentrations increase until they level out around the $3^{\text {rd }}$ year. As a consequence, the $\mathrm{Cs} / \mathrm{Sr}$ value of the different items steadily decreases through time : it goes from 100 in the juice in the first year to 0.7 at the end of 5 years of root transfer and then seems to stabilize.

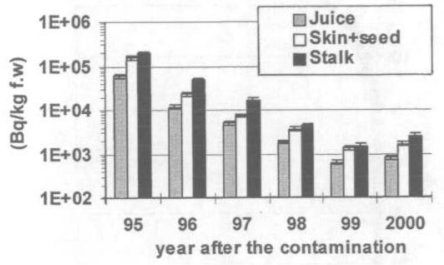

Figure $4 \mathrm{Cs}-137$ concentration in the different parts of bunches.

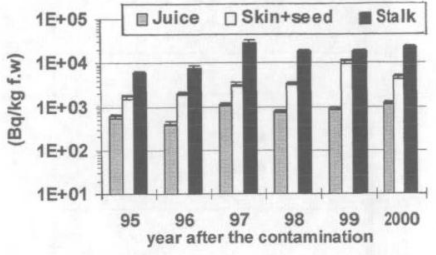

Figure $\mathbf{5}$ Sr-90 concentration in the different parts of bunches.

Leaves are more contaminated than shoots (Figure 6 and Figure 7) and even more than other parts of the vine. Bovard [6] presented similar results for cultivated soils. Throughout the experiment, Cs-137 activities in leave and shoots declined (Figure 6 and Figure 7). However, for strontium, the activity increases slightly and quickly levels out for leaves but fluctuates for shoots.

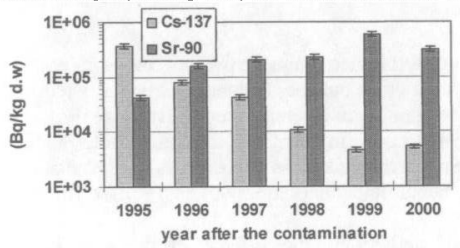

Figure 6 Development of $\mathrm{Cs}-137$ and $\mathrm{Sr}-90$ concentration in leaves

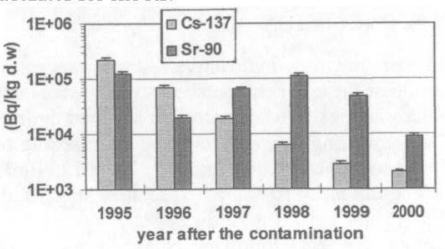

Figure 7 Development of Cs-137 and Sr-90 concentration in shoots

Several soil core bores between 1996 and 1999 enabled mean soil contamination to be estimated (75 \pm $47 \mathrm{MBq} / \mathrm{m}^{2}$ for $\mathrm{Cs}-137$ and $52 \pm 24 \mathrm{MBq} / \mathrm{m}^{2}$ for $\left.\mathrm{Sr}-90\right)$. The soil was not worked, therefore the contamination was not homogenised, and a soil-plant transfer coefficient for grape juice was defined in the following manner :

$\mathrm{Ft}=\frac{\text { Juice activity }(\mathrm{Bq} / \mathrm{l})}{\text { Soil activity }\left(\mathrm{Bq} / \mathrm{m}^{2}\right)}$

The transfer coefficient undergoes a reduction through time from $8.1 \times 10^{-4}$ to $1.1 \times 10^{-5}$ for Cs-137 and from $1.2 \times 10^{-5}$ to $2.3 \times 10^{-5}$ for $\mathrm{Sr}-90$. The $\mathrm{Cs}-137$ availability in soil (averaged over the first 20 centimetres) shows a reduction through time, which may explain a reduction in activity of Cs- 137 in different parts of the vine plant; in addition, caesium migration to deep soil is lower than that of strontium (Figure 8), however both remain largely in the upper layers of the soil. This said active roots have a volume of soil that is more contaminated in strontium than in cesium, which may lead for some time to a greater strontium uptake. The availability of this element does not significantly vary. 

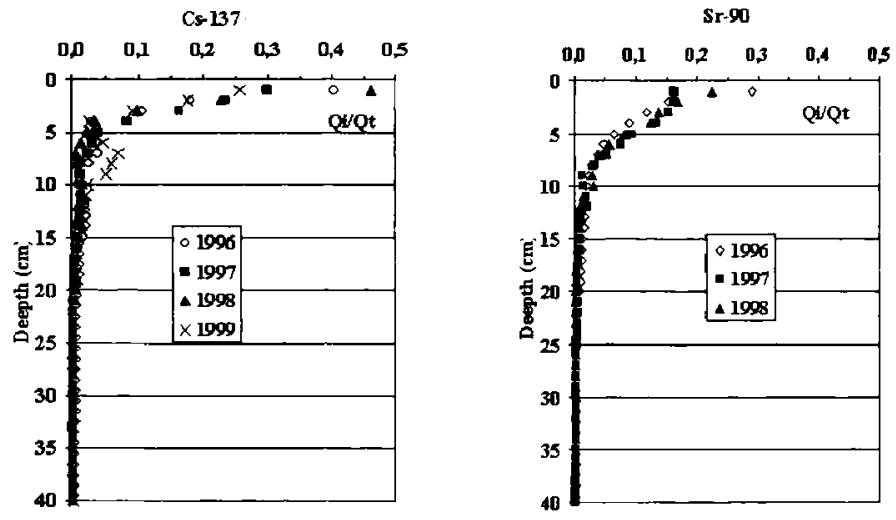

Figure 8 Migration of Cs-137 and Sr-90 through time. The values given on the axes are the reduced acrivities (activity of the layer under consideration over total core boring activity)

\section{CONCLUSION}

Contamination by radioactive aerosols was carried out on the vine plants at two vegetative stages. The results of these experiments show that the contamination of grape bunches and more particularly for grape juice was greater when pollution occurred during the "beginning of ripening" vegetative stage than at the "late flowering" vegetative stage. By referring to the EC marketing standard for consumable products, that is to say $1,000 \mathrm{~Bq} / \mathrm{l}$ for $\mathrm{Cs}-137$ and $125 \mathrm{~Bq} / \mathrm{l}$ for $\mathrm{Sr}-90$, the maximum deposit on a vine plantation at a " beginning of ripening " vegetative stage enabling bunch juice marketing will be $1.3 \times 10^{5} \mathrm{~Bq} / \mathrm{m}^{2}$ for $\mathrm{Cs}-137$ and $1 \times 10^{5} \mathrm{~Bq} / \mathrm{m}^{2}$ for Sr-90.

During the years following contamination, the Cs-137 activity for the different elements of the vine steadily decreases with time whilst the strontium activity slightly increases during the first years to level out at the end of 3 years. It appears that these variations may be linked to the migration and availability of radionuclides in the soil. For both radionuclides, the leaves and then shoots have stronger activities than those for the edible parts of the vine plants.

\section{References}

[1] Madoz-Escande C., \& al... Nuclear Science and Engineering, 133, (1999), pp 178-191.

[2] Tomos J., \& al,. Journal of Environmental Radioactivity, 27, No 3, (1995), pp 193-206.

[3] Zehnder H.J. \& al Proceedings of the International Symposium on Radioecology Ten years terrestrial radioecological research following the Tchernobyl accident' 22-24 April 1996, Vjenna

[4] Arapis G. $4^{\text {th }}$ International Conference on Environmental Science and Technology, Lesbos, Greece, 4 7 September 1995.

[5] Carini F. \& al. in Proceedings of the International Symposium on Radioecology 'Ten years terrestrial radioecological research following the Chernobyl accident' 22-24 April 1996, Vienna.

[6] Bovard P., Benard P., Delmas J. Grauby A. Académie d'Agriculture de France taken from the official report of the session dated 23 October, 1968. 